\section{A Case of Hydrocolpos}

\author{
W. G. DAWSON
}

British Medical fournal, 1973, 2, 155

Hydrocolpos has received little attention during the past decade (Dewhurst, 1963; Cook and Marshall, 1964). Consequently many doctors are not aware of this retention cyst of the vagina and when seen it is often misdiagnosed. On the other hand the related disorder of haematocolpos usually found at puberty is well known and more often suspected than confirmed.

Cook and Marshall (1964) recalled that of the 49 cases of hydrocolpos in infants under 10 months recorded up to date of their study only 26 were diagnosed before treatment. The case mortality was $35 \%$. Of the 16 patients who underwent laparotomy when undiagnosed, eight had a hysterectomy because malignant disease was suspected.

In view of these startling figures a further case of hydrocolpos is reported.

\section{Case History}

The patient was a girl born at term, weight $61 \mathrm{~b} 150 z(3.24 \mathrm{~kg})$. The mother had given birth to a boy seven years previously who had been adopted.

She had discontinued an oral contraceptive two months before conception and the pregnancy and delivery were normal. The baby was breast fed and contented.

When seven days old a cystic dark swelling was noted at the vulva (see fig.). The child remained well. There was no apparent disturbance of micturition or defaecation and no abdominal tumour was felt. Vaginal examination confirmed the diagnosis of hydrocolpos.

The next day the hymen was incised to release a small quantity of clear fluid. At the same time the vagina was gently examined with a probe, and no septum was felt.

A five-day course of Ampiclox syrup (ampicillin/cloxacillin) 90 $\mathrm{mg}(0.6 \mathrm{ml})$ four-hourly was begun, and as the child's condition remained satisfactory with no further drainage from the vagina she was discharged from hospital with her mother on the ninth day after delivery.

The baby continued to thrive and when examined aged 1 month showed no abnormality of the external genitalia.

Princess Alexandra's R.A.F. Hospital, Swindon, Wiltshire

W. G. DAWSON, M.B., M.R.C.o.G., Squadron Leader, Senior Specialist in Obstetrics and Gynaecology

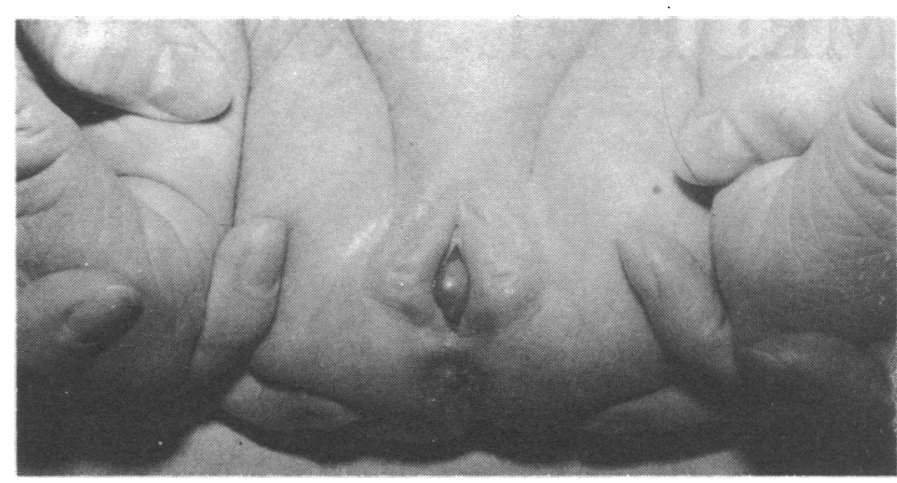

Cystic dark swelling at vulva of 7-day-old child.

\section{Comment}

This congenital lesion usually presents as an abdominal mass with signs of urinary obstruction. There may be associated urogenital abnormalities or other congenital malformations. In half the cases there is no prominence of the hymen.

The diagnosis is made by vaginal examination. In cases when an obstruction higher in the vagina is suspected this can be confirmed by noting that the cervix cannot be seen by vaginal endoscopy.

The treatment is usually by incision of the hymen. When there is a high vaginal obstruction a combined abdominoperineal approach is necessary, first to drain the vagina from above and then to establish a free connection with the lower vagina.

Hydrocolpos is due to excessive cervical secretion in the presence of an intact hymen or other vaginal obstruction. Vaginal cell desquamation may also contribute to the fluid. Obstruction to the urinary, alimentary, venous, and lymphatic systems, and respiratory embarrassment are secondary phenomena. Hydrocolpos may even cause gross abdominal distension of the female fetus so that dystocia results. Spontaneous cure by rupture of the hymen is uncommon.

Instances of the effects of stimulation by maternal oestrogens are common in the neonate, as for example breast enlargement or vaginal bleeding. Since most cases of hydrocolpos also occur in the neonate there may be a similar aetiology, at least in so far as the increased cervical secretion is concerned.

\section{References}

Cook, G. T., and Marshall, V. F. (1964). Fourmal of Urology, 92, 127. Dewhurst, C. J. (1963). Gynaecological Disorders of Infants and Children, chap. 4. London, Cassell 